\title{
Dexamethasone versus a combination of dexamethasone and ondansetron as prophylac- tic antiemetic in patients receiving intrathecal morphine for caesarean section
}

\author{
Akpan Imeh ${ }^{1}$, Oladapo Olaniyi ${ }^{2}$, Olateju Simeon ${ }^{3}$,Odusoga Omotola ${ }^{4}$
}

1. Olabisi Onabanjo University Teaching Hospital, Sagamu,

Nigeria; National Orthopaedic Hospital Igbobi, Lagos, Nigeria.

2. Lagos State School of Anaesthesia, Badagry, Nigeria.

3. Obafemi Awolowo University I le-Ife, Nigeria.

4. Olabisi Onabanjo University Teaching Hospital, Department

of Obstetrics and Gynaecology, Sagamu, Nigeria.

\begin{abstract}
:
Background: Intrathecal morphine for caesarean delivery provides excellent postoperative analgesia but it is commonly associated with nausea and vomiting. This prospective, randomized, double blind study was carried out to compare the effectiveness of a combination of dexamethasone and ondansetron with dexamethasone alone for prevention of postoperative nausea and vomiting (PONV) following intrathecal morphine injection for caesarean section.

Methods: A total of 108 parturients aged 18-40 years for elective caesarean section were randomized into 2 groups ( $\mathrm{n}=54)$ to receive either intravenous dexamethasone $8 \mathrm{mg}$ (Group A) or a combination of intravenous dexamethasone 8mg and ondansetron $4 \mathrm{mg}$ (group B). The study drug for each group consisted of $0.5 \%$ hyperbaric bupivacaine and $0.2 \mathrm{mg}$ morphine. The primary outcome variables were postoperative nausea and vomiting (PONV) which were assessed for a period of 24 hours. The patient's vital signs were monitored and documented.

Results: The incidence of nausea and vomiting was significantly reduced in patients who received a combination of dexamethasone and ondansetron compared with dexamethasone alone ( $9.3 \%$ Vs 37\%, respectively, $\mathrm{P}=0.003)$.

Conclusion: This study showed that a combination of dexamethasone and ondansetron administered prophylactically significantly reduced the incidence of PONV in pregnant women on intrathecal morphine for caesarean section.

Keywords: Dexamethasone; Ondansetron; Nausea and Vomiting; Morphine; Caesarean Section.

African Health Sciences 2014; 14(2):453-459
\end{abstract}

DOI: http://dx.doi.org/10.4314/ahs.v14i2.23

\section{Introduction}

Postoperative nausea and vomiting (PONV) is a common and unpleasant side effects following surgery. There has been a decrease in the incidence of PONV over the years from

$60 \%$ associated with use of potential emetogenic anaesthetic drugs like ether and cyclopropane to approximately $30 \% 1,2$. However, in some high-risk patients the incidence is still as high as $70 \% 3,4$. General anaesthesia has long been known as causing a greater frequency and severity of PONV than regional anaesthesia 4.

\section{Corresponding Author: \\ Akpan Imeh \\ Department of Anaesthesia, \\ National Orthopaedic Hospital, \\ Igbobi, Lagos, Nigeria. \\ Phone: +234 805886 1688; \\ +2348035929834 \\ Email:imehak@yahoo.com}

Currently, a large proportion of surgical procedures are amenable to regional anesthesia, thus increasing its popularity. Since the early 1980s, intrathecal morphine for caesarean section has been used to provide excellent postoperative analgesia following its introduction into central neural blockade 5, 6. Use of opioids is associated with some major side effects such as PONV, pruritus, urinary retention and respiratory depression.

The etiology of PONV is multifactorial. Patient, anesthesia and surgery related factors have been identified. Various antiemetics have been used for PONV prophylaxis, and to date, no single drug has been found to be totally effective in antagonizing all receptor sites involved in emetic response.

Dexamethasone and ondansetron have proven to be good prophylaxis of PONV following orthopaedic, general and gynecological surgery $7,8,9$. Although the efficacy of dexamethasone as an antiemetic had been demonstrated in many studies, not much studies has been done concerning its combination with ondanset- 
ron for prevention of PONV in parturients receiving intrathecal morphine for caesarean section. Hence there is a need to determine the efficacy of this combination over dexamethasone alone. The findings from this study will serve as a local reference for other investigators in the future.

\section{Method}

The study was carried out at the Olabisi Onabanjo University Teaching Hospital, Sagamu, Nigeria following approval by the scientific and ethical committee of the hospital. The study was carried out on pregnant women, aged 18-40 years, ASA I or II singleton pregnancy at term undergoing elective caesarean section under spinal anaesthesia using a combination of morphine and bupivacaine. Exclusion criteria were patients known to have history of motion sickness, hypersensitivity to dexamethasone, ondansetron, morphine or bupivacaine, pregnancy induced hypertension (PIH) and multiple pregnancy. Others were glucose intolerance or gestational diabetes patients with established gastrointestinal diseases, patients who had taken opioids and antiemetics medications within the last 24 hours, and patients with contraindications to spinal anaesthesia. The sample size formula for the comparison of two proportions was used. The power of the study was $90 \%$, the $\alpha$ error $=0.05$, and the expected incidence of PONV in the control group (P2) was 0.44 from previous study. Approximate sample size per group was 52 and increased by $10 \%$ to provide for attrition making a total of $58 \mathrm{pa}-$ tients in each group. A written informed consent from each patient was obtained.

The study was a double blinded, randomized, prospective clinical trial in which both the patients and the attending anaesthetists were blinded to the study drugs. Patients were randomized to either dexamethasone alone (Group A) or a combination of dexamethasone and ondansetron (Group B) using the table of simple random numbers. Monitors were applied on the patients and baseline pulse rate, blood pressure, respiratory rate, oxygen saturation were taken and recorded. The blood pressure was measured with non-invasive automated machine (OMRON) while the oxygen saturation, pulse rate, and respiratory rate, were taken with NONIN comprehensive monitor. An intravenous access was established with either $16 \mathrm{G}$ or $18 \mathrm{G}$ cannula in a non-dominant forearm vein and the patient was preloaded with 5O0-1000 mL of Ringer's lactate solution over 20-30minutes before instituting the spinal anaesthesia.
The study drugs were dexamethasone, manufactured by Wuhan Pharmaceutical Group Company Limited,China,with NAFDAC Registration Number 04-6504, and NAFDAC Registration Number A4-0121. Dexamethasone $8 \mathrm{mg}$, and a combination of dexamethasone $8 \mathrm{mg}$ and ondansetron $4 \mathrm{mg}$, respectively, were drawn into identical syringes and diluted with sterile water to achieve a volume of $5 \mathrm{ml}$ by a senior resident anaesthetist who was not an investigator. The syringe containing dexamethasone $8 \mathrm{mg}$ was labelled group A, while that containing a combination of dexamethasone $8 \mathrm{mg}$ and ondansetron $4 \mathrm{mg}$ was labelled group B. These freshly prepared study drugs were handed over to the attending anaesthetist who was part of the investigation to administer to the patients (already randomized into group A and group B) before instituting spinal anaesthesia.

These prepared study drugs were administered intravenously by the attending anaesthetist before instituting the spinal block. Paturients were positioned sitting; skin preparation and draping were under aseptic condition. After locating L2 - 3 or L3 - L4 intervertebral space, the skin and interspinous ligaments were infiltrated with $2 \mathrm{ml}$ of $2 \%$ plain Lidocaine using $21 \mathrm{G}$ hypodermic needle. Subarachnoid block was established with a single bolus injection of a combination of 2.0 - $2.5 \mathrm{ml}$ of $0.5 \%$ hyperbaric bupivacaine (Astrazeneca) and $0.1 \mathrm{ml}$ of $0.2 \mathrm{mg}$ of preservative free morphine using $25 \mathrm{G}$ Whitacre spinal needle. After instituting the block, the patient was returned to the supine position with the head supported on a pillow with a left lateral tilt for uterine displacement and a slight head- up tilt to limit cephalad spread of the spinal agent. The vital signs (pulse rate, blood pressure, oxygen saturation and respiratory rate) were recorded every 2 minutes for the first 20 minutes and then every 5 minutes thereafter. Dermatomal sensory level was determined with the use of ice cubes and block up to T6 was considered adequate for caesarean section. Supplemental oxygen at 3Litres / min via nasal prongs was administered during the surgery and discontinued after delivery of the baby.

Nausea was defined as an unpleasant feeling associated with awareness of an urge to vomit. Vomiting was defined as the forceful expulsion of gastric contents from the mouth. Assessment of nausea and vomiting was done hourly for the first 4 hours and then 4 hourly for the next 20 hours. Nausea and vomiting occurring within the first 4 hours of surgery was considered early PONV while that occurring between 5-24 hours was considered as delayed or late PONV. For patients who 
had any episode of vomiting, a rescue antiemetic ondansetron $4 \mathrm{mg}$ intravenous bolus was given.

Statistical analysis was carried out using statistical software package SPSS version 15.0. Descriptive statistics of means and standard deviations were used for quantitative variables. T-test and chi-squared2) statistics were used as appropriate. P-value $<0.05$ was considered to be statistically significant.

\section{Results}

A total of 108 parturients, 54 in each group were studied out of the 116 recruited for this study. Eight patients were excluded from the study due to inadequate intraoperative analgesia and had the subarachnoid block (SAB) converted to general anaesthesia.The two groups were similar with respect to demographic characteristics as shown in Table 1.

\section{Table 1: Demographic Data}

Mean $\pm S D$

$\begin{array}{cllll}\text { Characteristics } & \begin{array}{l}\text { Group A }(n=54) \\ \text { Dexamethasone }\end{array} & \begin{array}{c}\text { Group } B(n=54) \\ \text { Dexamethasone }+ \\ \text { Ondansetron }\end{array} & \text { T-value } & \text { P-value } \\ & & \end{array}$

$\begin{array}{lllll}\text { Age(years) } & 31.80 \pm 5.25 & 30.85 \pm 4.85 & 1.02 & 0.31 \\ \text { Weight }(\mathrm{kg}) & 68.97 \pm 19.71 & 73.65 \pm 13.95 & 1.42 & 0.16 \\ \text { Height }(\mathrm{m}) & 1.64 \pm 0.07 & 1.63 \pm 0.06 & 0.14 & 0.89 \\ \text { BMI }\left(\mathrm{kg} / \mathrm{m}^{2}\right) & 28.26 \pm 4.17 & 28.4 \pm 4.29 & 0.19 & 0.85\end{array}$

For the patients' ASA status, 19 patients $(35.2 \%)$ were ASA 1 and 35 patients $(64.8 \%)$ were ASA II in the dexamethasone group while 38 patients( $71.7 \%$ ) and 15 patients $(28.3 \%)$ were ASA I and II respectively,in the dexamethasone and ondansetron group with a statistical significant difference $(\mathrm{P}<0.01)$. The mean duration of surgery was 60 minutes.

Table 2 shows mean baseline pulse rate, systolic blood pressure, diastolic blood pressure, respiratory rate and oxygen saturation for dexamethasone group(group A) and dexamethasone and ondansetron group(group B), with no significant statistical difference between the two study groups, $\mathrm{P}>0.05$. 


Characteristics $\quad \begin{aligned} & \text { Group A }(n=54) \\ & \text { Dexamethasone }\end{aligned} \quad \begin{gathered}\text { Group } B(n=54) \\ \text { Dexamethasone + } \\ \text { Ondansetron }\end{gathered} \quad$ T-value $\quad$ P-value

$\begin{array}{lllll}\begin{array}{l}\text { Respiratory Rate } \\ \text { (cycle/min) }\end{array} & 22.89 \pm 2.55 & 22.60 \pm 2.33 & 0.60 & 0.55 \\ \mathrm{SaO}_{2}(\%) & 98.26 \pm 0.76 & 98.19 \pm 0.68 & 0.51 & 0.61 \\ \text { Pulse Rate/min } & 93.74 \pm 13.63 & 92.38 \pm 10.16 & 0.59 & 0.56 \\ \text { Systolic Blood } & 129.37 \pm 14.30 & 125.58 \pm 9.72 & 1.60 & 0.11 \\ \text { Pressure }(\mathrm{mmHg}) & & & & \\ \text { Diastolic Blood } & 82.87 \pm 9.50 & 79.49 \pm 9.14 & 1.86 & 0.64 \\ \text { Pressure }(\mathrm{mmHg}) & & & & \end{array}$

Intraoperatively, oxygen saturation was above $98 \%$ in the two study groups, though all patients were routinely given oxygen till delivery of the baby. The trend of oxygen saturation was slightly higher in the dexamethasone and ondansetron group(group B). There were no significant changes in the intraoperative mean respiratory rate between the two groups, and also, there was no recorded episode of respiratory depression in any parturient. The intraoperative mean arterial pulse rates were similar in both study groups with no significant changes. There was no episode of bradycardia in any parturient. The intraoperative mean systolic blood pressure and mean diastolic blood pressure showed similar trend in the two groups, respectively. Although, 26 patients had hypotension overall(16 patients in the dexamethasone group and 10 patients in the dexamethasone and ondansetron group), 19 patients required treatment with intravenous ephedrine $3 \mathrm{mg}$ boluses to correct hypotension.

Table 3 shows that the frequency of emetic symptoms was significantly higher in the dexamethasone group compared with the dexamethasone and ondansetron group $(\mathrm{P}<0.05)$. All the emetic symptoms (nausea and vomiting) occurred early (0-4hours). Ten out of the 14 patients that vomited were given a rescue antiemetic ondansetron $4 \mathrm{mg}$ intravenous bolus. 


\begin{tabular}{|c|c|c|}
\hline & $\begin{array}{l}\text { Dexamethasone } \\
\text { no.(\%) } \\
n=54\end{array}$ & $\begin{array}{l}\text { Dexamethasone } \\
+ \text { Ondansetron } \\
\text { no. (\%) } \\
n=54\end{array}$ \\
\hline No PONV & $34(63.0)$ & $49(90.7)$ \\
\hline Nausea Only; Early 0-4 hours & $9(16.7)$ & $2(3.7)$ \\
\hline Late 5-24hours & - & - \\
\hline Vomiting or retching; Early 0-4 hours & $11(20.3)$ & $3(5.6)$ \\
\hline Late 5-24 hours & 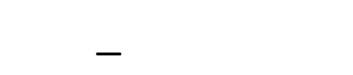 & - \\
\hline
\end{tabular}

Chi-squared $\left(x^{2}\right)$ value $=11.74$

$\mathrm{P}$-value $=0.003$

\section{Discussion}

Nausea and vomiting are among the most distressing symptoms in the postoperative period. Huang et al 10 had demonstrated a reduced incidence in PONV with prophylactic dexamethasone compared to placebo. Intravenous ondansetron $4 \mathrm{mg}$ has also been shown to significantly reduce the incidence of nausea and vomiting in pregnant women undergoing caesarean section under spinal analgesia 7,11. The results obtained from this study showed that the incidence of nausea and vomiting was significantly reduced with a combination of dexamethasone and ondansetron compared to dexamethasone alone $(9.3 \%$ and $37 \%$ respectively, $\mathrm{P}=$ 0.003). This result correlates with the pattern that had been reported by Szarvas et al and Lopez-Olaondo et al in separate studies.

Szarvas et al in their prospective, double-blinded randomized study found out that failure of PONV prophylaxis in the 24 hour postoperative period occurred more frequently in patients who received dexamethasone alone (29 of $40 ; 73 \%$ ) compared with those who received a combination of dexamethasone and ondansetron(19 of $43 ; 44), \mathrm{P}=0.01$. Dexamethasone is thought to have a late-onset antiemetic effect which might have contributed to its higher incidence of nausea and vomiting in this study. All the patients who had nausea or vomiting actually experienced them early (0-4hours). Therefore, in this study and in a previous study by Wang et al dexamethasone could be said to be ineffective against early PONV.

Better efficacy with use of combined antiemetic prophylaxis as seen in this study corroborates the findings of the meta-analysis of randomized controlled trials of combination of antiemetic therapy by Habib and . Their study showed no significant statistical difference in antiemetic efficacy when one of the 5-HT3 receptor antagonists is combined with either droperidol or dexamethasone and that both combination regime are significantly more effective than 5 -HT3 receptor antagonist alone.

There is an association between nausea, vomiting, and hypotension. Emetic symptoms could be triggered by hypotension and hypoxaemia15 of the brain stem due to spinal hypotension. Hypotension is the commonest immediate complication following spinal anaesthesia in obstetric patients. 
Patra et al noted that emetic symptoms were reduced in patients who developed post-spinal hypotension after being given 100\% oxygen, thus, implicating hypoxaemia at the emetic centre as a probable causative factor. There were no significant changes between the two groups with respect to maternal pulse rate, respiratory rate and oxygen saturation. Ephedrine was used in this study as the vasopressor of choice because it was readily available and on the basis that it does not appreciably affect uterine blood flow unlike the pure alpha adrenergic agonist phenylephrine which causes increase in uterine artery resistance and may reduce placental blood flow despite effective treatment of maternal hypotension .

Although a recent study has shown that such changes do not appear to have any effects on healthy parturients.

None of the patients in this study manifested any respiratory depression which was defined as respiratory rate $<10$ cycles/minutes probably because of the low dose intrathecal morphine $(0.2 \mathrm{mg})$ that was used for the study, though previous studies20,21 had reported that it was unlikely to have respiratory depression with low dose intrathecal morphine. Commonly reported side effects of ondansetron are headache, flushing at site of injection and constipation. No side effects of ondansetron were observed during the study.

\section{Conclusion}

The study demonstrated the efficacy of combining dexamethasone with ondansetron over use of dexamethasone alone as antiemetic prophylaxis in paturients receiving intrathecal morphine for caesarean delivery.

\section{Recommendation}

When parturients are undergoing caesarean delivery with intrathecal morphine, combination of antiemetics prophylaxis using dexamethasone and ondansetron should be considered because of its superior antiemetic quality.

\section{Limitation of the study}

Measurement of blood levels of the drugs used so as to know if therapeutic levels were reached could not be done because of lack of facilities.

\section{Acknowledgemet}

We are grateful to our teacher, Professor (Mrs) Olaitan
A. Soyannwo and the head of department, Dr (Mrs) O.M Fatungase, for their invaluable contributions to the success of this study

\section{References}

1. Gan T.J Postoperative nausea and vomiting- can it be eliminated? JAMA 2002; 287:1233-6

2. Janicki P. McCloud J, Evans D. Postoperative nausea and vomiting (PONV): A review article. Indian Journal of Anaesthesia, 2006:48(4): 253-258

3. Apfel CC, Laara E, Koivuranta M, Greim CA, Roewer N. A simplified risk score for predicting postoperative nausea and vomiting: conclusions from cross validations between two centers. Anesthesiology 1999; 91:693 - 700 .

4. Camu F, Lauwers M.H, Verbessem D. Incidence and Aetiology of postoperative nausea and vomiting. Eur J. Anaesthesiol 1992;9 (supp6)

5. Morgan M. The rational use of intrathecal and extradural opioids. Br J Anaesth.1989; 63:165-188.

6. Ben - David B, Solomon E, Levin H. Intrathecal fentanyl with small dose dilute bupivacaine: better anaesthesia without prolonging recovery. Anesth Analg1997;85:560-565.

7. Szarvas S, Chellapuri RS, Harmon DC, Owens J, Murphy D and Shorten GD. A comparison of dexamethasone plus ondansetron as prophylactic Antiemetic and Antipruritic therapy in patients receiving intrathecal morphine for major orthopaedic surgery. Anesth Analg 2003; 97(1); 259 -263.

8. Lee Y, lin PC, Lai HY, et al. Prevention of PONV with dexamethasone in female patients undergoing desflurane anaethesia for thyroidectomy. Acta Anaesthesiol Scand 2001;39:151-6.

9. Olatosi OJ, Kushimo O, Okeke C, Oriyomi O, Ajayi G.O. Antiemetic prophylaxis with promethazine or ondansetron in major gynaecological surgery. SAJAA 2008;14(6):39-42.

10. Huang JC, Shieh JP, Tang CS, Tzeng JI, Chu KS, Wang JJ. Low- dose dexamethasone effectively prevents postoperative nausea and vomiting after ambulatory laparoscopic surgery. Can J Anaesth 2001; 48:973-977.

11. Rajeeva V, Bhardwaj N, Batra Y.K, Dhaliwal L.K,. Comparison of Ondansetron with ondansetron and dexamethasone in prevention of PONV in diagnostic laparoscopy. Can J. Anaesth 1999;46(1):40-44

12. Lopez-Olaondo, Carrascosa F, Pueyo F.J, Monedero P, Busto N, Saez A. 
Combination of ondansetron and dexamethasone in the prophylaxis of postoperative nausea and vomiting. Br. J.Anaesth. 1996;76:835-840.

13. Wang JJ, HO ST, Liu HS, HO CM. Prophylactic antiemetic effect of dexamethasone in women undergoing ambulatory laparoscopic surgery. Br J Anaesth 2000;84: 459 - 462.

14. Habib AS, El-Moalem HE, Gan TJ. The efficacy of the 5HT3 receptor antagonists combined with droperidol for PONV prophylaxis is similar to their combination with dexamethasone. A meta-analysis of randomized controlled trials. Can J.Anaesth. 2004; 51:311-319.

15. Lee A, Ngan Kee WD, Gin T. A quantitative systematic review of randomized controlled trials of ephedrine versus Phenylephrine for the management of hypotension during spinal anaesthesia for caesarean delivery. Anesth Analg. 2002; 94: 920 - 926.

16. Morgan Pamela. Spinal Anaesthesia in Obstetrics. A review article Can J. Anaesth 1995; 42 (12): 1145-1163. 17. Patra CK, Badola RP, Bharga KP. A study of factors concerned in emesis during anaesthesia. Br J Anaesth. 1972; 44:1208 - 1211.

18. Erkinaro T, Kavasmaa T, M Pakkila, Acharya G, Makikallio K, Alahuhta S and Rasanen J. Ephedrine and phenylephrine for the treatment of maternal hypotension in a chronic sleep model of increased vascular resistance. Br J Anaesth. 2006; 96(2): 231-237.

19. Habib AS. A review of the impact of phenylephrine administration on maternal hemodynamics and maternal and neonatal outcomes in women undergoing caesarean delivery under spinal anesthesia. Anesth Analg. 2012; 114(2): 377-390.

20. Chaney M.A: side effects of intrathecal and epidural opioids. Can J Anaesth 1995, 891-903.

21. Abouleish E, Rawal N, Rashad MN. The addition of $0.2 \mathrm{mg}$ subarachnoid morphine to hyperbaric bupivacaine for caesarean delivery: a prospective study of 856 cases. Reg Anesth 1991; 16:137-140. 